\title{
The appliance of prefabricated soil-cement slabs processed with a hydrophobizing material for the road construction
}

\author{
Sergey Sannikov ${ }^{1}$, Sergey Kuyukov ${ }^{1}$, Alexey Zamyatin $^{1}$, and Alexandr Zhigailov ${ }^{1, *}$ \\ ${ }^{1}$ Department of highways and airfields, Tyumen Industrial University, Construction \\ Institute, 2, Lunacharsky St., Tyumen, 625039, Russia
}

\begin{abstract}
The paper presents a complex method for increasing water resistance and reducing crack formation by using a prefabricated foundation of soil-cement slabs with surface processing with a hydrophobizing material on basis of organosilicon compounds. Theoretical, laboratory and full-scale experimental studies were made. Theoretical studies are based on the substantiation of the geometric parameters of the slab in order to exclude the probability of its destruction under its own weight during building and installation works. The result of the first stage of laboratory studies is the determination of the optimum composition of soil-cement mixture in order to achieve a grade of strength M20. At the second stage, the effectiveness of the influence of hydrophobizing materials "Tiprom U" and "Penetron-Admix" on water absorption and compressive strength of soil-cement was determined. The final stage of the research was a full-scale experiment. In the factory environment, soil-cement slabs were manufactured in metal forms. Based on the results of the research, conclusions about the effectiveness of this complex method were made. The use of soil-cement slabs allows reducing crack formation, as well as to work all year round due to manufacturing and surface treatment of slabs in the factory conditions.
\end{abstract}

\section{Introduction}

In recent years, the fleet of vehicles has significantly increased and modified in Russia, which is connected with the availability of car purchases. As main reasons it is necessary to note the expanded crediting and various target programs. As part of the traffic flow, trucks with large payloads and significant axle loading appeared. The increase in intensity and the change in the composition of the flow require new approaches in the design and calculation of road covering of roads, as well as the use of new high-strength and durable materials, including soil-cement foundations, in the structures.

The road is a complex engineering structure, which includes many elements, the main of which are the soil foundation and road covering. It is the road covering that is the element on which condition the uninterrupted year-round transport connection depends.

\footnotetext{
* Corresponding author: zhigajlovaa@tyuiu.ru
} 
Unfortunately, in recent years, the applied constructions of road covering cannot be called diverse, especially the foundations.

For building the road foundations stone materials (ballast, gravel) are mainly used. The lack of stone material on the territory of many regions makes it necessary to transport gravel from neighboring areas by rail and then reload into dump trucks. This is the main reason for a significant rise in the cost of construction, as well as a decrease in the pace of production. One of the solutions to this problem is the replacement of imported stone materials with strengthened soils $[1,2]$.

To strengthen the soil can be used a large number of materials based on mineral (cement, lime, ash), organic binders (bitumen, bitumen emulsion), synthetic polymer compounds (stabilizers, polymer additives), production waste (slimes). Complex, electrochemical and thermal strengthening is also known [3-12].

The choice of the method of strengthening depends on many factors, including the type of soil, the area of construction, and the technology of production.

The most common is the build of soil-cement foundations. Soil-cement is a composite material obtained during the hardening of the optimum ratio of soil, cement and water.

There are two ways to build a soil-cement foundation. The first one is based on the preparation of the mixture directly on the construction site by mixing with a milling cutter or recycler, and the second one is the preparation of the mixture in a soil mixing plant. The quality of mixing of the components according to the second method is much higher, which affects the strength of the construct in use.

To ensure the durability of the road construction with soil-cement foundation, it is necessary to correctly select the initial materials (soil and stabilizer) and their dosages for further preparation of the mixture in the installation.

A significant disadvantage of soil-cement foundation when you are working in a structure is low water resistance and durability, as well as susceptibility to crack formation [13-16]. The main cause of these defects is the increased porosity of the material, and the complex natural-climatic and soil-geological conditions.

As methods to increase water resistance, it should be noted: the laying of the base material "in a cage"; use of modified soil-cement; installation of a roll waterproofing; application of waterproofing mastics, bitumen-latex emulsions, chemical elements, carbomide resins, petroleum products, microsilica. The method of reducing crack formation is the installation of expansion seams. All these methods have a number of significant disadvantages [17-19].

\section{Objects and methods of research}

To improve the water resistance, as well as reduce crack formation, a complex method is proposed. It is the use of a prefabricated foundation of soil-cement slabs with surface processing with a hydrophobizing material based on organosilicon compounds.

The slab consists of upper and lower contours, as well as beveled sides at an angle of $45^{0}$. The beveled sides ensure that each subsequent plate is supported on the previous one, which results in a uniform transfer of the load to the underlying layers.

The hydrophobization of slabs allows reducing water absorption due to the formation of a water repellent particles on the surface of the products, and the production of slabs in the factory - to produce a soil-cement foundation at the temperatures is below zero.

To confirm the effectiveness of this method, theoretical, laboratory and field studies were made. 


\section{Theoretical research}

Theoretical researches are based on the substantiation of the geometric parameters of the slab in order to exclude the probability of its destruction under its own weight during construction and installation works. As estimated scheme, a scheme was adopted with the application of a concentrated load in the center of the slab.

The working capacity of the slab during the ascent is estimated by the assurance factor:

$$
K_{a}=\frac{M_{\text {per }}}{M_{\max }}
$$

$M_{\text {per }}$ - permissible moment, arising when the slab is raised, $\mathrm{kN} * \mathrm{~m}$;

$M_{\max }-$ maximum moment, $\mathrm{kN} * \mathrm{~m}$.

To ensure additional design reliability, the assurance factor should be at least 1.3 to avoid destruction in the event of possible errors in the calculations and the technology for manufacturing the slabs.

When performing calculations, the thickness of the slab was assigned with reference to the recommended thickness of the bases of road foundation. The width of the slab was assigned to the multiple width of the base of road foundation.

The density of the slab used in the calculations is taken from the results of laboratory researches $[12,17,19]$.

Based on the results of calculations, it was found that, taking into account traffic intensity and loads for roads, it is recommended to use slabs with dimensions of $0,75 \times 1,0$ $\mathrm{m}, 0,75 \times 1,5 \mathrm{~m}$ with a tensile strength at bending $400 \mathrm{kN} / \mathrm{m} 2$ (grade of strength M20); for sidewalks and bicycle paths $0,75 \times 0,75 \mathrm{~m}$ and $0,75 \times 1,0 \mathrm{~m}$ with tensile strength at bending $200 \mathrm{kN} / \mathrm{m} 2$ (grade on strength M10).

\section{Laboratory research}

To confirm the theoretical researches at the Department of highways and airfields, works on the production of soil-cement slabs grade of strength M20 with improved properties, consisting of three stages were carried out.

The purpose of the first stage of the researches was to determine the optimum composition of soil-cement mixture to achieve a grade of strength M20. For this purpose, the composition of the soil-cement mixture was selected by molding the samples of four series [20]. The first series - samples with $6 \%$ content of cement from the mass of the soil; the second $-8 \%$; the third $-10 \%$; the fourth $-12 \%$. As a soil, fine homogeneous sand was used with the following characteristics: maximum density $-1687 \mathrm{~kg} / \mathrm{m} 3$, with an optimum humidity of $12,2 \%$. Samples were made on a small instrument of the standard compaction UnionDORNIAS. Tests of the samples were made after 28 days from the moment of their manufacture.

The results of the tests showed that the required grade of strength corresponds to samples of the second and third series with 8 and $10 \%$ cement content. For further studies, the cement content was taken as $10 \%$, since with a cement content of $8 \%$, the strength of the samples is close to the lowest value corresponding to the M20 grade, and with a minor technology violation, the claimed grade may not be achieved (figure 1). 


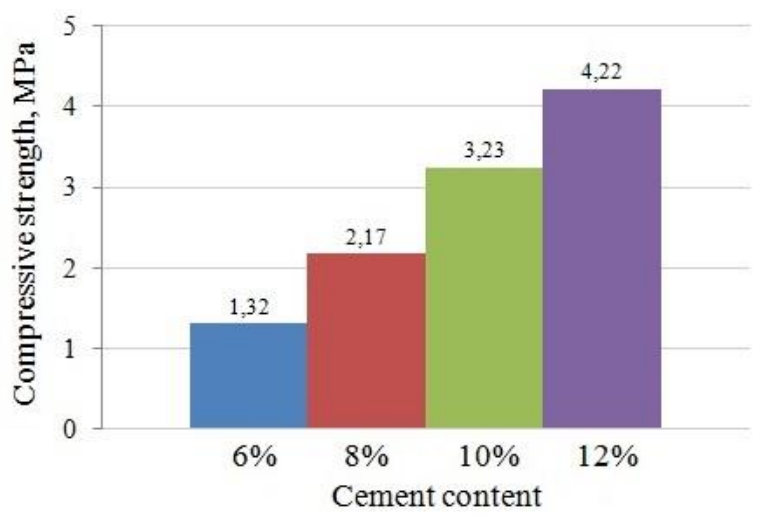

Fig. 1. Dependence of compressive strength on cement content

At the next stage of the researches, works were carried out to confirm the effectiveness of hydrophobizing materials, such as a liquid hydrophobizer based on organosilicon compounds "Tiprom U" and a dry additive "Penetron-Admix". As a result, four series of samples with a cement content of $10 \%$ were molded. The first series - control samples (without treatment with hydrophobizators); the second - with volumetric application of "Penetron-Admix" (10\% of cement mass); the third - with surface treatment of "Tiprom U"; the fourth - with a complex application of "Penetron-Admix" (10\% of the mass of cement) and surface treatment with "Tiprom U". In accordance with the technical recommendations developed by manufacturers of hydrophobizated additives, the time for maintaining the samples in a liquid hudrophobizator is 3 seconds. To evaluate the effect of hydrophobizing additives, the samples were tested for strength.

The results of the tests showed that samples of the third series possess the lowest value of water absorption, while corresponding to the grade of strength M20 (figure 2). The highest compressive strength is typical for the fourth series, but the water absorption in such samples is $1,59 \%$ more than in the third series. The last statement is due to the fact that the entering of "Penetron-Admix" has practically no effect on water absorption and, with the complex effect of hydrophobizing materials, reduces the effectiveness of "Tiprom U".

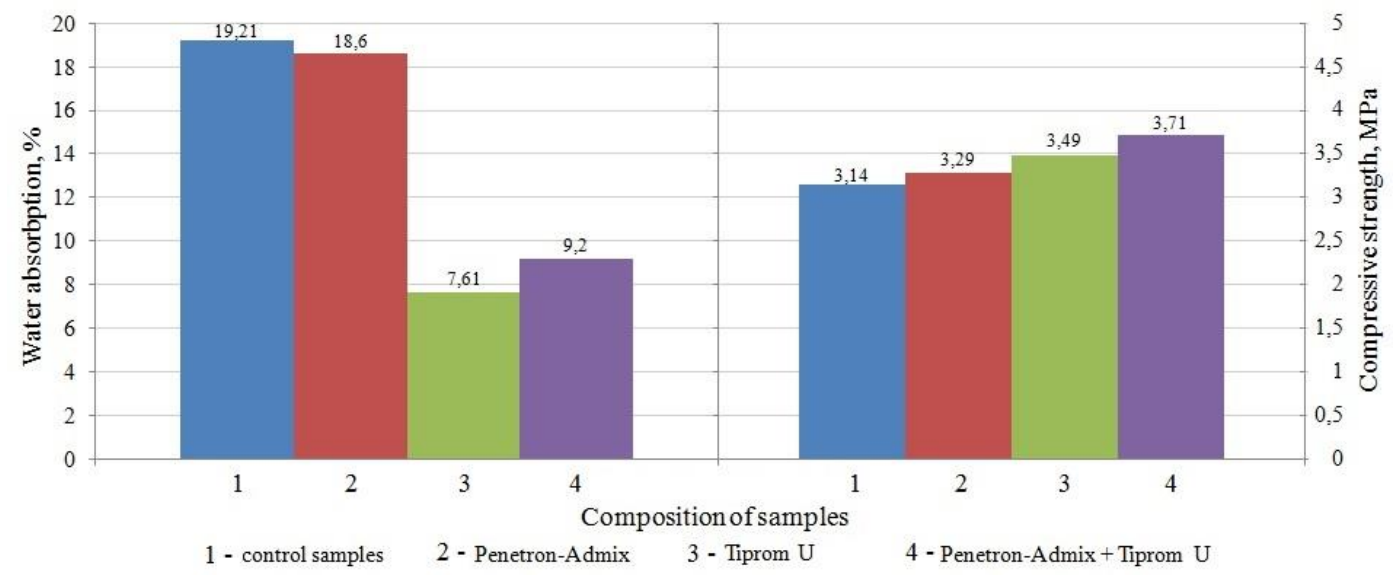

Fig. 2. Dependence of water absorption and compressive strength on the composition of samples 


\section{Full-scale experiment}

In August 2017, in order to confirm laboratory tests, a full-scale experiment (the third stage) was carried out at the production facility of the JSC "TODEP" DRSU-4. At the factory metal forms with dimensions of $0,75 \times 1,00 \times 0,18(B \times L x h, m)$ were manufactured. The composition of the mixture was adopted in accordance with the prescription, justified by laboratory tests. Preparation of the mixture was carried out in a gravity-type concrete mixing machine with a volume of $0,5 \mathrm{~m}^{3}$. In total, three slabs were made.

The manufacturing technology of slabs included: preparation of the mixture, laying the mixture into a form followed by compaction with a vibratory plate, forms removal, surface treatment of slabs with a hydrophobizator using a sprayer (figure 3). To ensure a set of grade strength after processing, the slabs were closed with a film and held for 28 days.

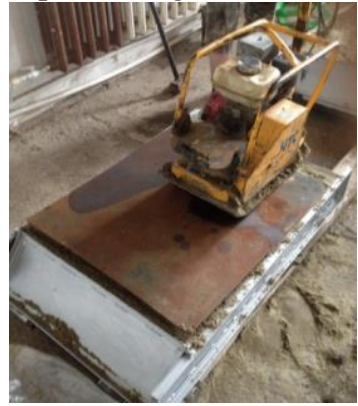

a)

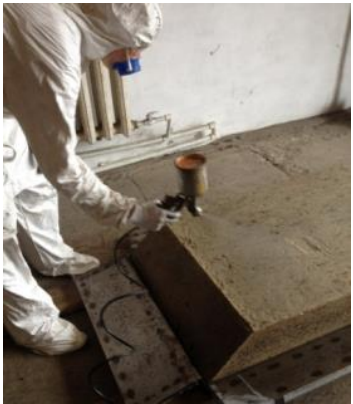

b)

Fig. 3. Manufacturing of slabs

a) compaction of the mixture in the form; b) surface treatment of slabs with a hydrophobizator.

After reaching the specified age, the external state of the slabs was assessed and markings were made in accordance with the loading scheme. Two metal supporting structures from below were installed, axially from above an equilateral corner was fixed on which a power measuring device with manometer was placed. A jack was placed on the upper stop of the power measuring device. To ensure uniform transfer of the load, the jack was rested against the support beam (figure 4). The whole process of testing was accompanied by video fixing. The load transfer to the slab was continued until transversal distortion. The values of the destructive load were 15,$0 ; 13,8 ; 14,3 \mathrm{kN}$. The average value of the tensile strength was $0,43 \mathrm{MPa}$, which corresponds to the grade on strength M20.

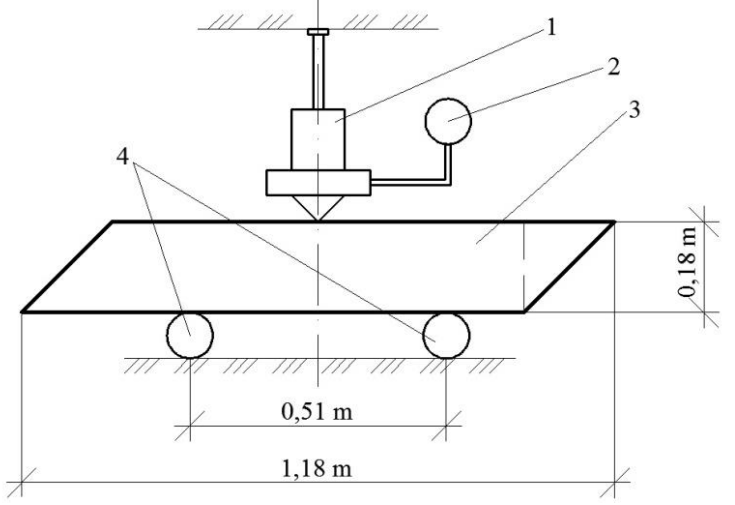

Fig. 4. General view of the loading scheme for testing the slabs 1 - the jack; 2 - power measuring device with manometer; 3 -slab; 4 - metal supporting structures. 
From each slab, sample-cubes were selected for the subsequent determination of compressive strength and water absorption.

The results of the tests showed that the highest compressive strenght have samplecubes, with surface treatment of hydrophobizator (3,27 MPa, which is 1,12 times more than in control samples). The maximum decrease in water absorption was marked on the hydrophobizing samples-cubes (from 19,89 to $9,54 \%$, which is 2,08 times less than in the control samples) (figure 5).

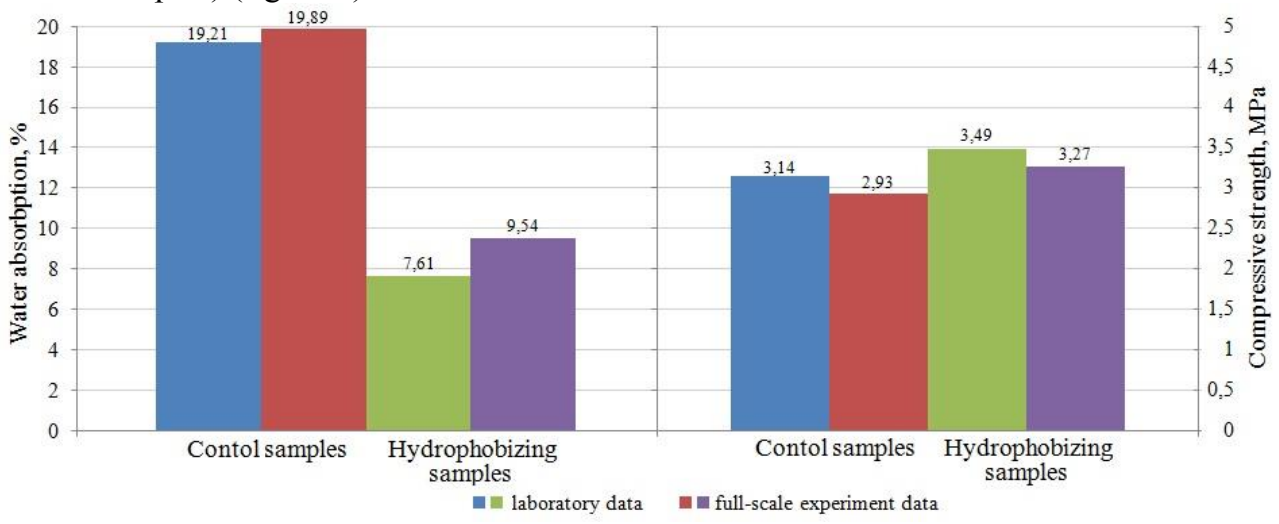

Fig. 5. Results of laboratory tests and full-scale experiment

When comparing the results of laboratory and full-scale researches, the deviations in water absorption were $0,68-1,93 \%$, in compressive strength $6,73-7,16 \%$. Deviations from laboratory data are due to the conditions for the manufacture of samples.

The test results of the slabs confirmed their applicability for the construction of foundations and additional layers of road covering for roads, sidewalks and bicycle paths in accordance with the requirements of the normative literature.

\section{Conclusion}

Analyzing the results of theoretical, laboratory researches and full-scale experiment, we can draw the following conclusions:

- ensuring the water resistance of road constructions with a soil-cement foundation is an essential goal in the design and construction of roads;

- a complex method for increasing water resistance and reducing crack formation is proposed due to the use of a prefabricated foundation of soil-cement slabs with surface treatment with a hydrophobizing material;

- calculations have been made, which allow to substantiate the geometrical dimensions of slabs;

- laboratory research have been performed, which allow to determine the composition of the mixture for the slabs;

- approbation have been performed of the proposed complex method for the manufacture and testing of soil-cement slabs.

It is determined that:

- the surface treatment of slabs with the hydrophobizator "Tiprom U" increases the water resistance of soil-cement slabs by $2-2,5$ times without significant change in strength;

- the use of prefabricated soil-cement foundation with surface treatment with a hydrophobizator, will allow to reduce crack formation, as well as to work all year round 
due to manufacturing and processed of slabs in the factory conditions.

\section{References}

1. V.M. Bezruk, Strengthening of soil (Moscow, Publishing house of the Transport, 340, 1965)

2. V. M. Bezruk, Strengthening of soil in road and airfield construction (Moscow: Publishing house of the Transport, 247, 1971)

3. V.B. Balabanov, K. N. Putsenko, IOP Publishing Ltd, 262 (2017)

4. D.V. Ulrikh, M. D. Butakova, Procedia Engineering Cep., 1510-1515 (2016)

5. L. Mavliev, P. Bulanov, E. Vdovin, V. Zaharov, A Gimazov, ZKG: ZEMENT-KALKGIPS INTERNATIONAL, 69 (2016)

6. V.B. Balabanov, K N Putsenko, D Munchausen, SJ "Izves. vuz. Invest. Constr. Realty“, 7, 3, 107-115 (2017)

7. A.I. Trautwein, A. E. Akimov, E. A. Yakovlev, E. A. Chernogil, A. G. Lukashuk, Vest. of Belg. STU named of V. G. Shukhova, 12, 6-13 (2017)

8. V.V. Yadykina, A. M. Gridchin, R. O. Antonova, Efficient construction composites, 767-770 (2015)

9. N.P. Sigachev, N.A. Konovalova, P.P. Pankov, D.A. Efimenko, D.A. Grigoriev, Vest. of the Zab. St. Un., 7, 28-36 (2015)

10. A.A. Ramazanov, A.D. Badaeva, E.B. Lanin, T.A. Alnashash, Constr. of un. Build. and struct., 3, 111-128 (2015)

11. P.P. Pankov, N.A. Konovalova, O.N. Dabizha, Mod. high tech., 11, 52-57 (2017)

12. S.P. Sannikov, A.A. Zhigalov, V.S. Andreev Sc.-tech. Vest. of the Vol. Reg., 1, 132134 (2015)

13. A.O. Tyulenev, A.V. Zamyatin, New technologies for the oil and gas region: proceedings of the international scientific and practical conference, 339-341 (2017)

14. E.A. Vdovin, L.F. Mavliev, Ind. And Civ.Eng., 11, 76-79 (2014)

15. N.A. Konovalova, P.P. Pankov, D.V. Bespalov, A.G. Konovalov, A.I. Kozhukhovsky, Tran. Infr. of the Sib. Reg., 1, 152-155 (2016)

16. A.V. Annenkova, New technologies for the oil and gas region: proceedings of the international scientific and practical conference, 223-226 (2017)

17. S.P. Sannikov, S.A. Kuyukov, A.A. Zhigailov, Actual problems of architecture, construction, energy efficiency and environment in 2016: a collection of materials of international scientific-practical conference, 144-149 (2016)

18. N.P. Sigachev, N.A. Konovalova, V.I. Konnov, P.P. Pankov, N.S. Efimenko, Ec. And Ind. of Rus., 11, 24-27 (2015)

19. A.A. Zhigailov, New technologies for the oil and gas region: proceedings of the international scientific and practical conference, 243-247 (2017)

20. V.V. Nalimov, N.A. Chernova, Statistical methods of planning extreme experiments (Moscow: Publishing house of the Science, 341, 1965) 